\title{
ADOÇÃO DA CERTIFICAÇÃO LEED EM MEIOS DE HOSPEDAGEM: ESVERDEANDO A HOTELARIA?
}

\author{
ADOPTING LEED CERTIFICATION IN LODGING FACILITIES: GREENING THE HOSPITALITY \\ INDUSTRY \\ ADOPCIÓN DE LA CERTIFICACIÓN LEED EN MEDIOS DE HOSPEDAJE: ¿ENVERDECIENDO LA HOTELERÍA?
}

\section{RESUMO}

A pesquisa objetivou analisar o processo de adoção da certificação "Leadership in Energy and Environmental Design" (LEED) a partir dos estabelecimentos do setor hoteleiro que já a adotaram. Para sua concretização procedeu-se uma pesquisa bibliográfica, coleta de dados secundários em sites institucionais, periódicos e material documental, bem como de dados primários por meio de entrevistas semiestruturadas. Foram 21 entrevistados, sendo 02 do Green Building Council Brasil e 19 de meios de hospedagem (31\% dos certificados). A análise deu-se por meio da análise de conteúdo com auxílio do software ATLAS.ti. Os resultados permitiram identificar a cronologia dos processos de certificação e o perfil das categorias hoteleiras que adotam o programa $L E E D$. Além disso, as entrevistas possibilitaram a discussão das motivações iniciais de busca pela certificação, bem como as vantagens e os entraves percebidos quanto à sua adoção.

PALAVRAS-CHAVE Meios de hospedagem, sustentabilidade, construções verdes, certificação, LEED.

Mirna de Lima Medeiros mirnamedeiros@hotmail.com

Doutoranda em Administração pelo Programa de Pós-Graduação em Administração de Organizações pela Faculdade de Economia, Administração e Contabilidade de Ribeirão Preto, Universidade de São Paulo - Ribeirão Preto - SP, Brasil

Danielle Fernandes Costa Machado daniellefcm@gmail.com

Professora do Instituto de Ciências Humanas, Universidade Federal de Juiz de Fora - Juiz de Fora - MG, Brasil e Doutoranda em Administração pelo Programa de Pós-Graduação em Administração, Universidade Federal do Rio Grande do Sul - Porto Alegre - RS, Brasil

João Luiz Passador jlpassador@usp.br

Professor da Faculdade de Economia, Administração e Contabilidade de Ribeirão Preto, Universidade de São Paulo - Ribeirão

Preto - SP, Brasil

Cláudia Souza Passador cspassador@usp.br

Professora da Faculdade de Economia, Administração e Contabilidade de Ribeirão Preto, Universidade de São Paulo - Ribeirão Preto - SP, Brasil

Abstract The research intended to analyze the adoption process of the green certification "Leadership in Energy and Environmental Design" (LEED) from the hotel sector establishments that has already adopted it. For its concretization it was proceeded a bibliographical research, secondary fact-gathering in journals, institutional sites and documentaries, and primary fact-gathering by means of semi structured interviews carried out with responsible people of the certified hotels and of the responsible entity of the certification in Brazil (Green Building Council Brazil). There were 21 interviewee, being 02 of the GBC Brazil and 19 of means of lodging (31\% of the certified). For data analysis, it was utilized content analysis technique with the aid of ATLAS.ti software. The results permitted to identify the chronology of the processes of certification and the profile of the hotel categories that adopt the LEED program. Beyond that, the interviews enabled the discussion of the initial motivations for seeking the certification, as well the advantages and the obstacles perceived regarding its adoption.

Keywords Means of lodging, sustainability, green building, certification, LEED.

Resumen La investigación tuvo como objetivo analizar el proceso de adopción de la certificación "Leadership in Energy and Environmental Design" (LEED) a partir de los establecimientos del sector hotelero que ya la adoptaron. Para su concreción se procedió a una investigación bibliográfica, recolección de datos secundarios en sitios web institucionales, periódicos y material documental, y recolección de datos primarios por medio de entrevistas semiestructuradas. Fueron 21 entrevistados -02 del Green Building Council Brasil y 19 de medios de hospedaje (31\% de los certificados)-. El análisis se dio por medio del análisis de contenido con ayuda del software ATLAS.ti. Los resultados permitieron identificar la cronología de los procesos de certificación y el perfil de las categorías hoteleras que adoptan el programa LEED. Además, las entrevistas posibilitaron la discusión de las motivaciones iniciales de busca por la certificación, así como las ventajas y los obstáculos percibidos respecto a su adopción.

Palabras clave Medios de hospedaje, sostenibilidad, construcciones verdes, certificación, LEED. 


\section{INTRODUÇÃO}

As discussões sobre sustentabilidade, embora não sejam tão recentes, ganharam maior propulsão a partir da década de 1990, em decorrência, sobretudo, do agravamento da crise ambiental. Nesse sentido, o debate tem abarcado uma série de contextos, incluindo os setores de construção civil e da indústria hoteleira, que são apontados, em muitos casos, como grandes consumidores de recursos naturais. Apesar da relevância do tema sustentabilidade em construções para a hotelaria, o debate acadêmico sobre o assunto ainda está restrito, principalmente, às áreas de arquitetura, urbanismo e engenharia. Acredita-se, no entanto, que esse esforço analítico deva ser ampliado ao campo do turismo, com foco nas suas contribuições para o desenvolvimento socioambiental da atividade.

$\mathrm{Na}$ atual conjuntura econômica brasileira, esse debate torna-se ainda mais profícuo tendo-se em vista a expansão hoteleira. De acordo com a Associação Brasileira da Indústria de Hotéis (ABIH), no Brasil, existem cerca de 18 mil meios de hospedagem, que totalizam aproximadamente 1,1 milhão de unidades habitacionais, e os negócios do turismo já representam $4 \%$ do PIB, sendo que a hotelaria oferece mais de 500 mil vagas de emprego diretas. Além disso, com a previsão de realização de eventos de grande relevância internacional, como a Copa do Mundo e as Olimpíadas, reconhece-se que, para atender a demanda de turistas, será necessário um aumento significativo de empreendimentos hoteleiros no País. Nesse sentido, várias ações privadas e públicas já foram iniciadas com o intuito de incrementar a oferta de linhas de crédito para a construção dos meios de hospedagem.

Diante do breve panorama, a presente pesquisa buscou analisar o processo de adoção da certificação LEED com base nos estabelecimentos do setor hoteleiro que já a adotaram. Mais especificamente, verificou-se a existência de hotéis certificados e em processo de certificação, analisando seu processo histórico e suas tendências de crescimento, bem como as principais vantagens e entraves percebidos para sua adoção.

A presente pesquisa tem sua importância ressaltada ao se considerar que a indústria hoteleira é um dos nichos do turismo que mais consomem energia e recursos. Apesar disso, o tema da certificação verde aplicada aos meios de hospedagem ainda é incipiente na literatura brasileira. Nesse sentido, defendem-se aqui a originalidade, a atualidade e a pertinência do estudo proposto, na medida em que a certificação
LEED ainda não foi obtida por nenhum empreendimento no Brasil. No mundo, embora seja um dos programas de certificação mais bem reputados, apenas 58 meios de hospedagem possuem esse selo. Por sua vez, considera-se que a pesquisa é atual na medida em que parece haver um crescimento no número de organizações que pleiteiam a certificação enfocada. Pensar e discutir esse tipo de certificação pode ser útil para diversas áreas da gestão de organizações. O presente trabalho opta por fazer uma análise que contribua com a gestão socioambiental das organizações. Finalmente, considera-se que o trabalho possa instigar o desenvolvimento de pesquisas, bem como de uma certificação mais completa que possa ser estendida aos diversos ramos do turismo, tornando as certificações menos suscetíveis às práticas de greenwashing e mais reconhecidas como parâmetro para escolha da hospedagem.

\section{METODOLOGIA}

Optou-se pela pesquisa qualitativa, em que, mesmo sendo utilizados dados quantitativos, estes têm caráter descritivo. Para a obtenção das informações, utilizaram-se fontes de dados primárias e secundárias. $\mathrm{Na}$ primeira fase da pesquisa, foi feita a revisão da literatura e, em seguida, foram realizadas entrevistas semiestruturadas, via chamadas telefônicas e correio eletrônico, com representantes do Green Building Council Brasil, bem como análise documental de alguns materiais disponibilizados (LEED project diretory, Green venue selection guide, Guia para sua obra mais verde, bem como materiais de divulgação e relatórios institucionais). Por fim, procedeu-se à coleta de dados nos sites dos meios de hospedagem certificados (58) e análise documental de releases de meios de hospedagem certificados (26). Essa etapa permitiu o delineamento do perfil, época de certificação e localização dos meios de hospedagem que possuem a certificação em tela. Esse diagnóstico do quadro atual, além de interessante por si só, permitiu a análise contextualizada dos dados obtidos na segunda fase.

Para execução da etapa subsequente, $e$-mails foram enviados aos 58 estabelecimentos cuja certificação não era sigilosa (em outubro de 2010), contendo uma apresentação da proposta de trabalho e questões abertas que deveriam ser respondidas por pessoas com conhecimento suficiente sobre a temática e o processo dentro 
do meio de hospedagem. As questões referiam-se a cinco dimensões: (a) motivo da certificação, (b) tempo de duração do processo de certificação, (c) percepção de pontos positivos, (d) percepção de pontos negativos ou entraves, e (e) valorização da certificação pelos clientes do estabelecimento. No entanto, a dimensão "b" foi excluída das análises devido a divergências de interpretação, além de alguns respondentes não saberem fornecer essa informação precisamente.

Obteve-se um total de 19 respostas $(31 \%$ de retorno). O grupo de respondentes foi composto por homens e mulheres, que foram designados pelo estabelecimento por estarem aptos a responder pelo hotel às questões submetidas. Assim, o grupo foi composto de pessoas que ocupam cargo de diretoria, supervisão ou gerência. Com vistas a preservar as pessoas e estabelecimentos envolvidos na pesquisa, os respondentes foram mantidos anônimos e foram designados pela letra $\mathrm{H}$ e um número (que designa a ordem de recebimento da resposta). Ainda assim, uma caracterização dos respondentes é apresentada, pois se acredita que as respostas podem ser mais bem entendidas dentro de um contexto. Além disso, ao se exporem as percepções de segmentos específicos, estratégias de mercado ou demandas de públicos-alvo específicos podem ser inferidas e servir de inspiração para estudos posteriores.

Optamos pelo uso da análise de conteúdo (AC) auxiliada pelo software ATLAS.ti (versão 6.0). A opção deu-se por se tratar de um conjunto de instrumentos metodológicos que se aplicam a discursos (conteúdos e continentes) extremamente diversificados (BARDIN, 1977). A organização da análise seguiu o modelo de três etapas sugerido pela autora: pré-análise, exploração e tratamento de dados e interpretações.

\section{POR QUE TORNAR A HOTELARIA MAIS VERDE?}

Os conceitos de crescimento e desenvolvimento econômico vêm se sobrepondo ou se confundindo ao longo dos últimos dois séculos. Desde o advento da revolução industrial, na segunda metade do século XVIII, na Inglaterra, emoldurada pela superestrutura do Estado de Direito, o homem vem construindo conceitos e ferramentas com o pressuposto de que, finalmente, ele conseguiria superar sua longa história de fome, miséria e subserviência aos caprichos da natureza. Pelos ideais do renascimento europeu, especialmente embasados nos pressupostos das ciências modernas, havia a forte expectativa e, em muitos casos, a convicção de que se realizaria, finalmente, o sonho da Machina Mundi de Renè Descartes, embarcado no método indutivo de Francis Bacon. Esse último afirmava ser a ciência a caixa de ferramentas úteis para torturar e arrancar da natureza os seus segredos. $\mathrm{E}$, assim revelados, esses segredos passariam a compor os corolários da ciência a subjugar a caprichosa natureza a favor dos interesses do homem moderno.

A tais pressupostos agregava-se, supostamente, a ideia de que seriam inexauríveis os recursos dessa natureza domesticada, ou que ela teria capacidade ilimitada de renovação e recomposição de seus estoques. Não foram necessários muitos anos, dentro da perspectiva ampla do processo civilizatório, para se perceber, por evidências de difícil contestação, que esses pressupostos estavam severamente equivocados. O uso exponencial e as evidências de finitude de uma grande parcela dos recursos naturais fizeram soar vozes alarmadas sobre os riscos eminentes à perpetuação da vida no planeta Terra. O colapso é destino certo se as mudanças de hábitos de consumo e tecnologias de produção não sofrerem significativas mudanças (SCOTTO, CARVALHO, GUIMARÃES, 2007).

A noção de desenvolvimento nunca foi consensual e vem sendo empregada durante séculos como sinônimo de crescimento, limitando-se aos aspectos econômicos. Para Veiga (2005), a nebulosidade da expressão gera confusões. Por esse motivo, sugere três respostas à indagação "o que é desenvolvimento?". A primeira é cognominar o desenvolvimento como sinônimo de crescimento econômico. A segunda é tratar a expressão como uma ilusão, crença, mito ou manipulação ideológica. A última e a mais complexa resposta é o desafio de pensadores deste século para encontrar um caminho do meio, que não se poderia restringir à renda per capita, devendo abranger questões culturais, sociais, entre outras (VEIGA, 2005).

Esse terceiro entendimento aproxima-se das discussões quanto ao desenvolvimento sustentável. Esse conceito decorre das críticas ao uso do conceito de desenvolvimento anteriormente preponderante e requer, segundo Sachs (2004), uma mudança de paradigma. O "Relatório Brundtland", documento "Nosso futuro comum", pode ser considerado grande marco dessa transição (VEIGA, 2005). Em tal documento, desenvolvimento sustentável apresenta-se como "aquele que atende às necessidades do presente sem comprometer a possibilidade de as gerações futuras atenderem a suas 
próprias necessidades" (COMISSÃO MUNDIAL SOBRE MEIO AMBIENTE E DESENVOLVIMENTO, 1991, p. 46).

Esse marco conceitual decorreu de conceitos anteriores, entre os quais se destaca o ecodesenvolvimento, que já vinha sendo defendido desde os anos 1970 e continuou sendo discutido e complexificado incluindo adjetivos como econômico, social, político, cultural, sustentável etc. (SACHS, 2004; VEIGA, 2005). Para Sachs (2004), os atuais pilares do desenvolvimento sustentável são: atender simultaneamente aos critérios de relevância social, prudência ecológica e viabilidade econômica.

É nesse contexto que estudos de impacto ambiental, planejamento de políticas integradas, desenvolvimento de tecnologias conservacionistas apropriadas e ações coordenadas de gestão ambiental vêm sendo desenvolvidos, mais intensamente, nas últimas duas décadas. Todos os ramos da atividade humana, de transformação à satisfação de necessidades intangíveis, vêm se mobilizando para desenvolver esses novos padrões. Alguns mais acentuados, em geral os de maior risco, como o setor energético, outros com menor velocidade de mudança. Porém, não há organização social de produção ou setor de atividade econômica que não deva desenvolver políticas de responsabilidade socioambiental, dentro dos seus projetos prioritários. Multiplicaram-se, nas carteiras de instrumentos de gestão, processos de certificação na área ambiental, com avaliações de conformidade cada vez mais sofisticadas quanto aos meios e mais rigorosas quanto aos fins (GUERRA e PÁJARO, 2011).

Assim, o conceito de desenvolvimento descolar-se-ia e tornar-se-ia relativamente autônomo ao de crescimento. Ganhos líquidos sobre bases tecnológicas e gerenciais constantes significam simplesmente crescer. Desenvolver-se pressupõe ruptura e evolução dessas bases que vão produzir bem-estar e sustentabilidade para as comunidades de interesse, ligadas aos empreendimentos econômicos de todos os ramos. E, mais particularmente ainda, aos esforços de correção ambiental e sustentabilidade também das construções (FRANCH, IZQUIERDO, TORRES, 2007; MARGOLIS e WALSH, 2003; RETTAB, BRIK, MELLAHI, 2009).

O termo construção sustentável foi proposto originalmente para descrever a responsabilidade da indústria em buscar a sustentabilidade nas edificações (HILL e BOWEN, 1997). Na literatura especializada, os elementos-chave encontrados na definição do termo são: eficiência do uso dos recursos; eficiência energética; conservação das áreas naturais e da biodiversidade; harmonização ambiental por meio da manutenção da qualidade do ambiente construído e de um exterior saudável; prevenção da poluição; e abordagens integradas e sistêmicas. De acordo com John, Clements-Croome e Jeronimidis (2005), o direcionamento da indústria construtiva para o desenvolvimento sustentável apoia-se na reciclagem e conservação dos recursos; no melhoramento da durabilidade das estruturas e no uso e aproveitamento de subprodutos de outras indústrias. Estudiosos salientam que as construções verdes (sustentáveis) pressupõem inúmeras práticas e atitudes que buscam uma qualidade integral em toda a vida útil das construções, contemplando os aspectos de desempenho econômico, social, ambiental e técnico (HILL e BOWEN, 1997; JOHN, CLEMENTS-CROOME, JERONIMIDIS, 2005). Assim, preocupam-se com impactos da construção, em relação a si mesma, às imediações e aos horizontes regionais e globais mais amplos.

Sobre as vantagens financeiras na adoção de construções verdes, a pesquisa de Katz (2003) demonstrou que, em comparação a construções convencionais do mesmo padrão, as construções verdes apresentam um aumento nos custos em curto prazo (de até 6,5\%, dependendo do nível). Contudo, há significativa redução dos gastos em longo prazo e otimização do desempenho financeiro, gerando uma economia média de U\$ 538,15 a U\$ 699,60 por metro quadrado construído.

O setor hoteleiro não poderia ficar à margem desse processo. É uma atividade econômica de alta exposição mercadológica e elevado índice de sensibilidade quando se trata de aparatos que, em grande medida, envolvem e dependem da natureza, especialmente nas suas dimensões estética e de sustentabilidade (GUERRA e PÁJARO, 2011). A construção de hotéis verdes é um nicho em expansão não somente porque esses estabelecimentos se diferenciam de similares não verdes, mas também pelo fato de preencherem uma necessidade do mercado por possibilidades de desfrute de produtos turísticos ambientalmente menos impactantes (BUTLER, 2008; FONT, 2008; FREITAS e ALMEIDA, 2010; MANAKTOLA E JAUHARI, 2007).

Tzschentkr, Kirk e Lynch (2004) verificaram que a possibilidade de redução de custos pelo aumento da eficiência operacional é um dos principais motivos por trás da introdução de medidas ambientais, e os aumentos sobre as taxas de água, energia e resíduos são fatores que impulsionam a busca por alternativas. A questão ética e social expressou-se na forma de simples obrigação moral, desejo de contribuir ou na citação "fazer a minha parte para as futuras gerações". Foster, Sampson e Dunn (2000) complementam listando 
forças que pressionariam a indústria da hospitalidade, bem como outros setores de serviços, a se tornarem ecoamigáveis: demanda do consumidor; regulação ambiental crescente; preocupação gerencial com a ética; satisfação do consumidor; questões da manutenção da planta física; e necessidade estética. O quadro apresentado pelos diversos autores indica que a implantação de certificações ambientais é financeiramente compensadora, fazendo com que as empresas tenham, além desse benefício direto, um tipo de benefício indireto: o reconhecimento de sua ação e a possível valorização da sua reputação.

\section{CERTIFICAÇÕES VERDES}

Segundo Kuhre (1997) e D'Souza (2004), além das certificações ambientais (eco-labels), há pelo menos mais dois tipos: os selos coordenados pelo governo e as autodeclarações. As certificações ambientais são um selo de aprovação de uma qualidade ambiental que foi verificada por avaliadores, preferivelmente independentes (SASIDHARAN, SIRAKAYA, KERSTETTER, 2002; WASIK, 1996). Segundo D'Souza (2004), também podem ser fornecidos por organizações públicas e privadas sem fins lucrativos que delineiam padrões e certificam os produtos que atingem certos standarts.

Os produtos e serviços ambientalmente certificados podem ser categorizados segundo três atributos: conexão entre fabricante e vendedor; espontaneidade da participação (voluntária ou obrigatória); promoção dos atributos (positiva, negativa ou neutra) (D'SOUZA, 2004; EPA, 1998). Ainda podem ser divididos, segundo Wasik (1996), de acordo com os critérios que os rótulos utilizam: atributo individual; selo de aprovação; informação de perigo; relatórios ou inventários de ciclo de vida. O autor propõe, ainda, uma certificação de abordagem mais holística que envolva a avaliação dos processos, bem como as atitudes corporativas.

O processo de certificação ambiental, em geral, envolve quatro passos: definição dos requisitos para obtenção do selo; verificação do cumprimento dos padrões estabelecidos; certificação por uma terceira parte (corpo avaliador) e acreditação. O propósito do processo supramencionado é levar à aceitação e reconhecimento pelos empreendedores, para a busca voluntária pela certificação, e pelo mercado, para que a certificação seja tomada como um símbolo de qualidade que influencie no comportamento de compra (FONT, 2002).
No contexto do turismo brasileiro, a utilização de selos é relativamente recente, principalmente se realizada de modo mais abrangente e sistemática por uma terceira parte. Alguns exemplos encontrados no País são: a norma ISO 14001, que certifica o sistema de gestão ambiental (SGA) em qualquer tipo de negócio; a autodenominação Roteiros de Charme, de uma rede de hotéis independentes que adotam um código de conduta ambiental; a Green Globe, que oferece três modalidades de serviços: afiliação, avaliação de desempenho e certificação propriamente dita; o Programa de Certificação do Turismo Sustentável (PCTS), que compreende a elaboração da Norma NBR 15.401 "Meios de hospedagem - Requisitos para a sustentabilidade"; o "Selo Verde de Sustentabilidade" aferido pelo Guia Quatro Rodas desde 2008, que destaca os estabelecimentos que seguiram algum tipo de ação sustentável. Em 2009, o selo verde passou a adotar critérios baseados em regras do Leadership in Energy and Environmental Design (LEED), do Green Building Council (GBC) e do Green Star Accreditation, da Austrália, órgãos que são referência na certificação de empreendimentos sustentáveis (INSTITUTO DE HOSPITALIDADE, sem data JANÉR, 2010; ZAMBONIM, 2002).

Apesar da existência de fundamentos balizadores que orientam os processos de certificação, no turismo, observa-se uma falta de métodos, bem como inconsistência de critérios padronizados e certificadores independentes, que assegurem que estes não são apenas greenwashing (FONT, 2002; KASIM, 2004). Há mais de 100 certificações verdes para turismo e hospitalidade, muitas das quais se sobrepõem em alguns quesitos. Várias iniciativas surgiram, com diferentes qualidades, critérios, conteúdos e escopo, causando tanta confusão que alguns consumidores preferem ignorá-los (FONT, 2002; LUBBERT, 2001; KASIM, 2004). Diante dos problemas gerados por essa profusão de declarações verdes e da necessidade de reconhecimento por parte de empreendedores e clientes, os programas de certificação em turismo devem empenhar-se no cumprimento dos passos do processo de certificação e oferecer garantias ao público da verificação independente dos selos (D'SOUZA, 2004; FONT, 2002; MUSKA, 1998). Nesse contexto, até que ponto é possível possuir processos de desenvolvimento sustentável? Em que medida as organizações certificadoras abordam um desenvolvimento sustentável? O texto a seguir descreve uma dessas certificações e analisa a sua adoção com base em impressões de empreendimentos que a adotam. 


\section{A CERTIFICAÇÃo LEED}

LEED é a sigla em inglês para liderança em energia e design ambiental, que é um programa de certificação e benchmarking para design, construção e operação de construções verdes de alta performance. Foi criado e é gerido pelo GBC dos Estados Unidos (USGBC) para reconhecer a liderança na concepção de ambientes, tanto comerciais quanto residenciais, quer na construção ou renovação. Sua primeira versão foi lançada em 1998, no entanto o ferramental está em aperfeiçoamento e adaptação constante, sendo que a versão mais atual é o $L E E D$ v.3, lançado em 2009. Há, ainda, as adaptações regionais, como ocorre no Canadá e Índia, por exemplo, e no Brasil, cujas adaptações propostas seriam expostas no ano de 2010, porém ainda não houve a sua divulgação, e onde a representação é feita pelo GBC Brasil, que iniciou suas atividades em junho de 2007. O LEED promove uma abordagem total da construção reconhecendo cinco áreas-chave de saúde ambiental e humana: seleção de materiais e recursos; energia e atmosfera; desenvolvimento de espaço sustentável - site; qualidade ambiental interna; uso racional da água; e uma área opcional de inovação em design (GBC, 2008; USGBC, 2009).

O programa certifica edifícios ou comunidades que foram construídos utilizando estratégias para a melhoria da performance, nos quesitos supracitados, com uma nota de sustentabilidade ambiental. Nesse sistema de certificação, os estabelecimentos que alcançam a pontuação equivalente ou superior a 40 entre os pontos disponíveis no checklist de quesitos são considerados certificados e podem alcançar quatro níveis: certified, silver, gold e platinum (USGBC,2009).

O LEED firmou-se nos EUA como o sistema de avaliação mais influente e vem exportando essa influência para outros países; comparado a outras certificações, é mais realista, pois engloba toda a edificação e não apenas partes ou processos (HERNANDES, 2006; KOHLER, 1999; GBC, 2009). Os fatores do seu sucesso são: o seu efeito divulgador/catalisador de princípios sustentáveis e boas práticas; o consenso norte-americano de que não há sistema de avaliação tão difundido e utilizado como o $L E E D$, que conseguiu congregar as mais diversas classes de profissionais, esferas governamentais e setores de atividade econômica; apoio de instituições públicas em sua divulgação e fortalecimento nos EUA; credibilidade conseguida por meio da associação da imagem institucional do LEED com agências do governo, associação de normas técnicas etc.; World Green
Building Council (WGBC), que permitiu e incentivou a criação de diversos centros similares ao USGBC ao redor do mundo, criando versões locais de sistemas de avaliação fortemente influenciados pelo LEED norte-americano; o seu uso é facilitado por ser público, ter material básico disponível gratuitamente pela internet e ser considerado como relativamente fácil de aplicar (HERNANDES, 2006).

Segundo Kasim (2004), os hotéis possuem dois grandes estágios de impacto ambiental e social. O primeiro é o período de sua construção e o segundo, o de sua operação, manutenção e crescimento. Becker (2009) coloca que a certificação LEED em hotéis significa dar passos iniciais em ambos os estágios: na operação sustentável por meio do design e na construção verde do meio de hospedagem. Além disso, salienta que os padrões estabelecidos pelo LEED podem fornecer uma estrutura para que os hotéis atinjam um equilíbrio entre sustentabilidade e atendimento das expectativas dos hóspedes. Isso se daria pelo fato de o sistema de avaliação da $L E E D$ prover uma verificação independente das metas sustentáveis, mas também almejar prover ambientes mais confortáveis aos ocupantes das construções. Butler (2008) corrobora o posicionamento de Becker (2009), pois salienta que vários estudos demonstram que o custo para construção de hotéis certificados com $L E E D$ não é muito superior às abordagens convencionais, sendo que essas edificações certificadas são mais saudáveis e confortáveis para seus ocupantes e possuem uma operação mais barata.

Devido à falta parâmetros de certificações verdes independentes, os meios de hospedagem têm buscado os padrões e certificação LEED (BECKER, 2009; CROUS e outros, 2008. Segundo Becker (2009), em 2006, apenas dois meios de hospedagem eram certificados, porém, ao final de 2007, 117 estavam registrados almejando a certificação.

\section{RESULTADOS E DISCUSSÕES}

Em 2010, segundo dados da pesquisa, 58 hotéis eram certificados, sendo 55 localizados nos Estados Unidos, um no Chile, um no México e um no Sri Lanka. O Gráfico 1 apresenta a distribuição temporal da certificação de meios de hospedagem com a LEED.

Nota-se que a primeira certificação remete ao ano 2000. Em seguida, no período de 2003 a 2007, há alternância entre ocorrência e não ocorrência de certifi- 
cação: em 2003, foram duas, em 2005, seis e em 2007 , quatro. A partir de 2007, em todos os anos houve certificações. Fica claro, no Gráfico 1, que, a partir daquele ano, o número de meios de hospedagem certificados tem aumentado, sendo que em 2010 (até outubro) 20 estabelecimentos haviam sido contemplados com a certificação. Tal movimento ascendente pode significar um esverdeamento da hotelaria ou a necessidade de comprovar as práticas ecossocioamigáveis.

O porte é bastante variado. Há, por exemplo, um meio de hospedagem com oito unidades habitacionais (UHs) e outro com 4.004. De acordo com o número de UHs, os estabelecimentos podem ser divididos nas seguintes faixas: até 100 (18\%); entre 101 e 200 (43\%); entre 201 e 300 (20\%); entre 301 e 400 (5\%); entre 401 e 500 (2\%); entre 501 e 1.000 (5\%); e acima de 1.000 (7\%). Nota-se que a segunda faixa, entre 101 e 200 UHs, foi a que se apresentou com mais casos (43\%). Percebe-se, também, que a maior parte, $81 \%$, possui número de UHs inferior a 300.

Os meios de hospedagem certificados também foram divididos segundo a categoria a que pertencem. Adotaram-se, para tanto, as categorias as quais os estabelecimentos estudados utilizam para se autointitular. Dos 58, 38\% são hotéis ou resorts de luxo, 22\% são boutique hotéis de luxo, 29\% são de categoria superior, $4 \%$ são de categoria turística e $7 \%$ são econômicos. Nota-se que a maior parte dos meios de hospedagem certificados é de estabelecimentos que buscam altos padrões de serviços e ainda procuram ser únicos, como é o caso dos estabelecimentos boutique.

Respondentes representativos dos diversos portes e categorias foram indagados com relação à certificação. No Quadro 1, é exposta a caracterização dos indivíduos que colaboraram com a pesquisa. Suas funções, bem como meios de hospedagem que representam, podem interferir em sua percepção. Além disso, as percepções, quando analisadas contextualmente, podem dar indícios de estratégias de mercado ou de demandas de segmentos específicos.

Houve 13 motivos citados pelos 19 entrevistados como fator que levou à certificação (Quadro 2). Nota-se que os três mais citados podem ser relacionados diretamente com o consumidor e a imagem que a empresa pretende passar. Além dessas razões, pelo menos duas outras também estão explicitamente relacionadas ao mercado (I e VI). Ao buscarem atrair e/ou manter clientes, os meios de hospedagem, de certa forma, também estão buscando retornos financeiros. Assim, pelo menos seis razões podem ser ligadas a retornos almejados (I, IV, VI, XI, XII e XIII). Essa preponderância alinha-se com achados de Tzschentkr, Kirk e Lynch (2004), que analisaram a adoção de outra certificação e destacaram também as poucas menções a motivações de cunho ético e social.

Cinco razões podem ser consideradas decorrentes de valores e consciência socioambiental (III, V, VII, VIII e X), o que não quer dizer que desconsiderem o negócio e a necessidade de obter receitas. As razões III e VIII, por exemplo, podem ser indispensáveis para que a organização continue atuando, pois se referem ao local que o hospede visitará, e que, por sua vez, influenciam clima, segurança, beleza, atratividade, entre outras razões relacionadas às virtudes e diferenciais de

\section{Gráfico 1 - Evolução cronológica da certificação LEED em meios de hospedagem}

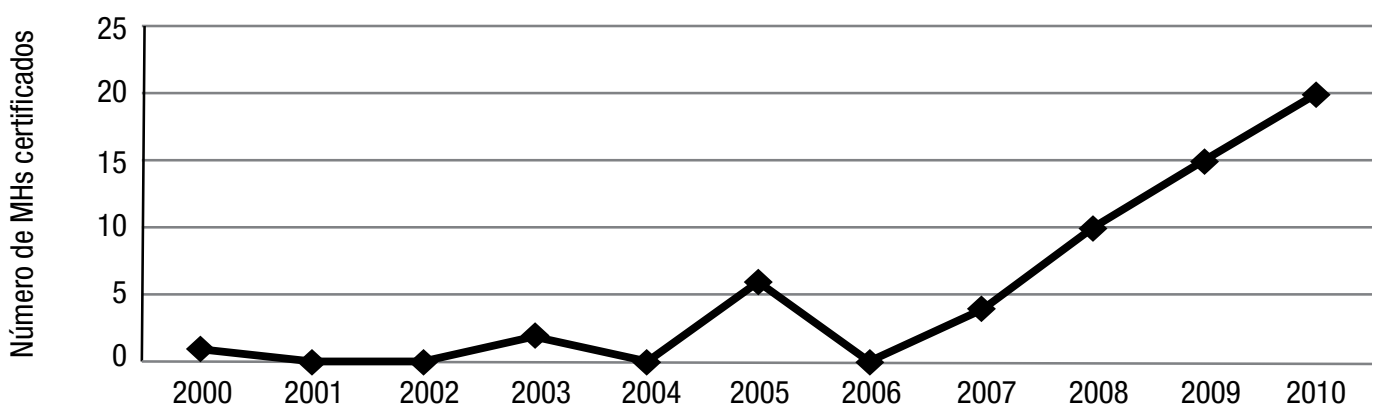

Ano de certificação 
oferta. Por fim, as razões II e IX apresentam a adoção da certificação por uma imposição.

As dimensões observadas demonstram atribuição de valores distintos à certificação, caracterizando-a como multifacetada. As menções a seguir demonstram essa diferença: valorizando a diferenciação, H3 menciona que "Quando decidimos construir, não havia nenhum outro hotel com LEED no estado. A certificação se mostrou como grande oportunidade de diferenciação da propriedade dos competidores"; H13 apresenta a questão da demanda do proprietário e busca por credibilidade: "A LEED serviu como confirmação maior do nosso compromisso tanto com construções sustentáveis quanto com práticas operacionais e foi uma resposta ao desafio do nosso grupo de proprietários que queriam ver se o luxo e sustentabilidade podiam coexistir"; já H14 foi o único a mencionar a relação com a comunidade: "Nossa comunidade também tem sido muito progressista, e esse tipo de inovação é uma expectati- va em uma construção nova. Os donos queriam criar uma forte conexão com a comunidade, e a certificação foi parte da construção de um bom relacionamento".

Quanto à percepção da certificação LEED, foram enumerados pelos respondentes pontos positivos (25) e negativos (8), como observa-se no Quadro 3. Houve maior número de citações positivas e, em alguns casos, quando respondiam sobre os pontos negativos, os entrevistados fizeram observações de que estes eram superados pelos benefícios. Entre os pontos percebidos mais citados, encontram-se o maior custo do projeto de um lado e, do outro, um menor custo operacional, o que corrobora os apontamentos de Katz (2003). Mais da metade dos respondentes aponta como benefício três fatores: economia de energia, o que é esperado, uma vez que a certificação em si chama-se Leadership in Energy and Environmental Design; criação de um ambiente mais saudável e confortável para os seus ocupantes, decorrente de melhorias de luminosidade, da

\section{Quadro 1 - Caracterização dos respondentes da pesquisa}

\begin{tabular}{|c|c|c|c|c|}
\hline & Função & Certificação & Categoria & Porte (em UHs) \\
\hline $\mathrm{H} 1$ & Assistente de Comunicação & Gold & Turística & Até 100 \\
\hline $\mathrm{H} 2$ & Diretor Geral & Certified & Boutique Hotel & Até 100 \\
\hline $\mathrm{H} 3$ & Diretor Regional & Certified & Boutique Hotel & Entre 101 e 200 \\
\hline $\mathrm{H} 4$ & Diretor de Operações Sustentáveis & Gold & Luxo & Entre 301 e 400 \\
\hline H5 & Diretor de Operações Sustentáveis & Gold & Luxo & Acima de 1.000 \\
\hline $\mathrm{H} 6$ & Diretor de Operações Sustentáveis & Gold & Luxo & Entre 501 e 1.000 \\
\hline $\mathrm{H} 7$ & Diretor de Operações Sustentáveis & Gold & Luxo & Acima de 1.000 \\
\hline $\mathrm{H} 8$ & Gerente de Serviços, LEED AP* & Platinum & Luxo & Entre 101 e 200 \\
\hline $\mathrm{H} 9$ & Diretor de Operações & Silver & Luxo & Entre 201 e 300 \\
\hline $\mathrm{H} 10$ & Gerente de Relações Públicas & Certified & Luxo & Entre 101 e 200 \\
\hline $\mathrm{H} 11$ & Gerente Geral & Certified & Superior & Entre 101 e 200 \\
\hline $\mathrm{H} 12$ & Gerente Geral & Certified & Luxo & Entre 201 e 300 \\
\hline $\mathrm{H} 13$ & Diretor de Sustentabilidade, LEEDAP* & Gold & Luxo & Entre 201 e 300 \\
\hline $\mathrm{H} 14$ & Gerente Geral & Gold & Boutique Hotel & Entre 101 e 200 \\
\hline H15 & Supervisor & Gold & Boutique Hotel & Até 100 \\
\hline H16 & Diretor de Vendas e Marketing & Certified & Superior & Entre 101 e 200 \\
\hline $\mathrm{H} 17$ & Gerente Geral & Silver & Econômico & Entre 101 e 200 \\
\hline H18 & Gerente de Relações Públicas & Silver & Luxo & Entre 101 e 200 \\
\hline H19 & Supervisor & Gold & Luxo & Entre 101 e 200 \\
\hline
\end{tabular}

* LEED AP é o profissional que teve seus conhecimentos acerca da certificação LEED atestados por um exame do GBC. 
qualidade do ar, do entorno, e todas as dimensões em que a $L E E D$ realiza análises; e menor custo, o que se alinha com as motivações de cunho financeiro e busca por longevidade do negócio.

Faz-se relevante expor algumas citações de profissionais que responderam às questões enviadas. H8 define o que acredita ser um edifício que possui $L E E D$ : "É simplificadamente um edifício que as pessoas querem usar". Justifica o fato dizendo que o conjunto de práticas torna o ambiente mais agradável aos ocupantes, quer sejam hóspedes, funcionários ou visitantes. H4 vai além na defesa da certificação: "Eu acho que a certificação LEED é uma ferramenta bastante útil para incorporação de medidas sustentáveis no desenvolvimento de projetos porque ela fornece a estrutura e cria responsabilidade fiscal (accountability). Ela também provê uma abordagem mais holística para a sustentabilidade porque considera todos os aspectos do design, construção e operações do edifício". Esse orgulho e defesa da certificação são percebidos também na resposta de H19: "A certificação LEED é um reconhecimento dos esforços de uma equipe que imaginou o meio de hospedagem como um projeto sustentável". Apesar de haver clara menção à dificuldade (exposta por alguns como entrave), esta deixa a certificação, de certo modo, mais valiosa.

O ponto negativo mais mencionado foi a necessidade de adequação da norma. No caso da hotelaria, esse desafio é premente, uma vez que os meios de hospedagem possuem espaços destinados aos mais variados usos (negócios, lazer, descanso, alimentação etc.) e podem ser bastante distintos entre si (em relação ao porte, categoria, localidade etc.). A necessidade de constantes explicações e adaptações pode causar descontentamentos, como o exposto por H18, que diz: "Deveríamos ser ranqueados como Gold, mas atingimos apenas a categoria Silver devido a dificuldades burocráticas e confusão em torno de diversos pontos da certificação $L E E D "$.

Além de questões positivas e negativas observadas, o H13 expõe a certificação como tendência, já que "há uma tendência a programar e executar boas práticas verdes em construções" e que "os hóspedes, tanto grupos quanto individuais, esperam agora que os hotéis estejam levando isso a sério". Todos os respondentes afirmam que a certificação é valorizada pelos consumidores, no entanto a percepção do grau de influência da certificação nas escolhas dos clientes é distinta. Na maioria dos casos (H1, H2, H3, H4, H5, H6, H7, H9, H10, H11, H13, H15, H17, H19), entendem que o seu cliente potencial conhece e deseja o selo, sendo que H9 comenta: "Acredito que os clientes valorizam a $L E E D$, pois esta é tida como a certificação ambiental mais respeitada no mundo atualmente. Como a palavra se espalha, os consumidores apreciam seus benefícios". Já H8 faz uma ressalva, dizendo que nem todos conhe-

\section{Quadro 2 - Motivos para a certificação LEED}

\begin{tabular}{|c|c|c|}
\hline & MOTIVAÇÃO & RESPONDENTES \\
\hline 1 & Ser uma opção de hospedagem ecoamigável & $\mathrm{H} 1$ \\
\hline$\|$ & Demanda governamental & $\mathrm{H} 12$ \\
\hline III & Estabelecer um bom relacionamento e laço com a comunidade local & $\mathrm{H} 14$ \\
\hline IV & Benefícios financeiros & $\mathrm{H} 14$ \\
\hline V & Criar um ambiente saudável para nossos hóspedes e funcionários & $\mathrm{H} 15$ \\
\hline $\mathrm{VI}$ & Assegurar que as declarações não sejam tidas como greenwashing & $\mathrm{H} 8$ \\
\hline VII & Fornecer exemplo e estimular as atitudes responsáveis & $\mathrm{H} 9, \mathrm{H} 10$ \\
\hline VIII & Diminuição do impacto e conservação do meio ambiente & $\mathrm{H} 1, \mathrm{H} 9, \mathrm{H} 15$ \\
\hline IX & Demanda do proprietário & $\mathrm{H} 11, \mathrm{H} 13, \mathrm{H} 14, \mathrm{H} 16$ \\
\hline$X$ & Alinhamento da certificação com os valores da empresa & $\mathrm{H} 10, \mathrm{H} 16, \mathrm{H} 17, \mathrm{H} 18, \mathrm{H} 19$ \\
\hline XI & Inovar & $\mathrm{H} 4, \mathrm{H} 5, \mathrm{H} 6, \mathrm{H} 7, \mathrm{H} 14$ \\
\hline XII & Dar credibilidade ao projeto e às práticas sustentáveis adotadas & $\mathrm{H} 4, \mathrm{H} 5, \mathrm{H} 6, \mathrm{H} 7, \mathrm{H} 8, \mathrm{H} 13, \mathrm{H} 19$ \\
\hline XIII & $\begin{array}{l}\text { Potencial de diferenciação/Vontade de ser o primeiro certificado (na cidade, no estado, no } \\
\text { país, no continente, de um tipo específico etc.) }\end{array}$ & $\mathrm{H} 2, \mathrm{H} 3, \mathrm{H} 4, \mathrm{H} 5, \mathrm{H} 6, \mathrm{H} 7, \mathrm{H} 10, \mathrm{H} 19$ \\
\hline
\end{tabular}




\section{Quadro 3 - Percepção quanto à certificação LEED}

\section{PONTOS POSITIVOS}

Sentimento de orgulho imbuído no staff

Atração de hóspedes

Retorno financeiro mais rápido

Luminosidade natural

Uso de materiais renováveis

Abatimento de impostos

Maior facilidade para receber permissões

Sentimento de posse imbuído nos hóspedes e funcionários e a conservação decorrente desse sentimento

Adição de valor na experiência do hóspede

Redução de resíduos

Fornecer um exemplo e estimular os demais a terem atitudes responsáveis

Atendimento a demanda dos hóspedes por hotéis socioecologicamente responsáveis

Benefício à comunidade local pelo uso de mão de obra e materiais locais

Retorno de hóspedes

Captação de eventos

Diminuição do impacto e conservação do meio ambiente

Dar credibilidade ao projeto e às práticas sustentáveis adotadas pelo meio de hospedagem

Maior produtividade e satisfação dos empregados decorrente de um melhor ambiente de trabalho

Aumento de lucros e/ou ações

Eficiência e alta performance

Economia de água

Melhoria da qualidade do ar

Economia de energia

Criar um ambiente mais saudável para nossos hóspedes e funcionários

Menor custo operacional

PONTOS NEGATIVOS

Requer mais esforço que os projetos tradicionais

Maior tempo gasto no projeto

Grande quantidade de documentos

Necessidade de coordenação e alinhamento entre todas as partes para assegurar 0 cumprimento das diretrizes

Ser complexo e requerer um especialista para guiar o processo

Materiais utilizados

Custo mais alto do projeto

Necessidade de interpretações e adaptações da norma
RESPONDENTES

H1

H11

$\mathrm{H} 12$

H15

H15

H15

H15

H2, $\mathrm{H} 3$

$\mathrm{H} 8, \mathrm{H} 11$

$\mathrm{H} 12, \mathrm{H} 17$

$\mathrm{H} 9, \mathrm{H} 10, \mathrm{H} 18$

$\mathrm{H} 1, \mathrm{H} 13, \mathrm{H} 14$

$\mathrm{H} 15, \mathrm{H} 18, \mathrm{H} 19$

$\mathrm{H} 4, \mathrm{H} 5, \mathrm{H} 6, \mathrm{H} 7$

$\mathrm{H} 4, \mathrm{H} 5, \mathrm{H} 6, \mathrm{H} 7$

H1, H12, H15, H18, H19

H1, H10, H11, H12, H13, H18

$\mathrm{H} 4, \mathrm{H} 5, \mathrm{H} 6, \mathrm{H} 7, \mathrm{H} 15$

$\mathrm{H} 4, \mathrm{H} 5, \mathrm{H} 6, \mathrm{H} 7, \mathrm{H} 15$

$\mathrm{H} 4, \mathrm{H} 5, \mathrm{H} 6, \mathrm{H7}, \mathrm{H} 14, \mathrm{H} 16$

$\mathrm{H} 4, \mathrm{H} 5, \mathrm{H6}, \mathrm{H7}, \mathrm{H} 15, \mathrm{H} 17, \mathrm{H} 19$

$\mathrm{H4}$, H5, H6, H7, H12, H15, H17, H19

$\mathrm{H} 4, \mathrm{H} 5, \mathrm{H} 6, \mathrm{H} 7, \mathrm{H} 8, \mathrm{H} 11, \mathrm{H} 12, \mathrm{H} 15, \mathrm{H} 17, \mathrm{H} 19$

$\mathrm{H} 2, \mathrm{H} 3, \mathrm{H} 4, \mathrm{H} 5, \mathrm{H} 6, \mathrm{H} 7, \mathrm{H} 8, \mathrm{H} 9, \mathrm{H} 10, \mathrm{H} 12, \mathrm{H} 14$

$\mathrm{H} 2, \mathrm{H} 3, \mathrm{H} 4, \mathrm{H} 5, \mathrm{H} 6, \mathrm{H} 7, \mathrm{H} 8, \mathrm{H} 9, \mathrm{H} 10, \mathrm{H} 12, \mathrm{H} 15, \mathrm{H} 16$

\section{RESPONDENTES}

$\mathrm{H} 10$

$\mathrm{H} 1, \mathrm{H} 15$

$\mathrm{H} 9, \mathrm{H} 12$

H9, H10

$\mathrm{H} 12, \mathrm{H} 15$

$\mathrm{H} 9, \mathrm{H} 11, \mathrm{H} 14$

$\mathrm{H} 1, \mathrm{H} 2, \mathrm{H} 3, \mathrm{H} 14, \mathrm{H} 15$

$\mathrm{H} 4, \mathrm{H} 5, \mathrm{H} 6, \mathrm{H} 7, \mathrm{H} 13, \mathrm{H} 17, \mathrm{H} 19$ 
cem a certificação: "A certificação é valorizada pelos hóspedes que a conhecem. Ainda assim, aqueles que não a conhecem experimentam seus benefícios ao se hospedar conosco".

Há caso em que o respondente cita que, apesar de valorizada e conhecida, a certificação não gera maior demanda: "A certificação LEED interessa à maioria, é valorizada por alguns, mas ainda não faz com que muitos clientes façam sua reserva conosco" (H12). Há também caso de percepções opostas em relação à possibilidade de incremento no valor de diárias. Enquanto H14 afirma que "a maioria não deseja pagar um valor adicional por um quarto somente por conta da certificação LEED. Eles a veem como uma boa 'regalia', mas não desejam pagar mais por isso", H10 salienta que "os hóspedes apreciam a oportunidade de gastar seus dólares em um lugar que faz a diferença".

As respostas de maior frequência quanto aos motivos para adoção da certificação LEED e quanto aos benefícios decorrentes dessa adoção estão em conformidade com estudos anteriores, que relacionam as ações de responsabilidade social coorporativa com a possibilidade de obtenção de maiores lucros, incremento da competitividade pela criação de ativos intangiveis (ORELLANO E QUIOTA, 2011; ORLITZKY, SCHMIDT, RYNES, 2003; RETTAB, BRIK, MELLAHI, 2009; WAGNER e SCHALTEGGER, 2003). Poucas são as menções que enfatizam a complementariedade da dimensão econômica com a social, conforme preconizado por Margolis e Walsh (2003) e Franch, Izquierdo e Torres (2007), o que abre espaço para questionar se essas ações estão sendo realizadas como uma simples ferramenta de marketing (HUSTED e DE JESÚS, 2006). Os benefícios enaltecidos atêm-se às áreas-chave preconizadas dentro da certificação em foco, mas não incluem outras dimensões desejáveis segundo as propostas de desenvolvimento sustentável e da responsabilidade social coorporativa decorrente da primeira, como as questões trabalhistas, os direitos humanos, a sociedade e a responsabilidade sobre os produtos, entre outras (GUERRA e PÁJARO, 2011; SACHS, 2004; VEIGA, 2005).

Após verificadas as percepções e características dos meios de hospedagem certificados, e tendo em mente que o que foi dito pode servir ou ter servido de incentivo a outros meios de hospedagem, é interessante também verificar os projetos cuja certificação encontra-se em andamento. Em 2010, pelo menos 257 projetos de meios de hospedagem estavam em processo de certificação LEED. O número exato tende a ser superior, pois são estimados 139 projetos confidenciais. Os projetos não confidenciais provêm de: Estados Unidos (201); China (15); México (14); Emirados Árabes (10); Oman (3); Coreia do Sul (2); Chile (2); Arábia Saudita (1); Brasil (1); Bahamas (1); Costa Rica (1); Espanha (1); Hungria (1); Jordânia (1), Polinésia Francesa (1); Santa Lucia (país caribenho) (1); e Tailândia (1).

A maior parte dos projetos em certificação é norte-americana, e imagina-se que o México apareça em terceiro pela proximidade e influência desse país. Nota-se que, em três dos quatro países em que atualmente existem meios de hospedagem certificados (EUA, México e Chile), há projetos em andamento. Nos dois primeiros, há um provável crescimento significativo. Além disso, projetos em novos países aparecem. China e Emirados Árabes, com 15 e 10 projetos, respectivamente, destacam-se pela quantidade de projetos em andamento. Esse último é notadamente um destino de alto luxo. Talvez por isso haja maior preocupação em atingir certos padrões em todos os sentidos, inclusive no quesito sustentabilidade. Verificou-se que empreendimentos hoteleiros sul-americanos já buscam a certificação: o Chile, que possui um certificado, está com mais um projeto em andamento; e o Brasil possui um projeto em andamento, o WTorre JK Hotel, em São Paulo. Além disso, há pelo menos dois outros países pertencentes à América do Sul com projetos confidenciais de certificação $L E E D$.

A propagação da certificação pode ser atribuída, entre outros vários fatores, às políticas de redes hoteleiras. Várias, incluindo algumas presentes no Brasil, já estão certificando hotéis fora do País, como é o caso das Accor, Hilton, Hyatt, InterContinental, Marriott, Preferred Hotels, Starwood, entre outras. Segundo entrevistado do GBC Brasil, em breve, essas redes provavelmente também certificarão no Brasil. Expôs, também, que, em 2009, gerentes do GBC Brasil participaram de, pelo menos, dois eventos destinados a hotéis, e nestes perceberam o aumento do interesse desse público, além de terem aprovado junto ao Comitê Olímpico Brasileiro a certificação dos hotéis que servirão às Olimpíadas 2016.

\section{CONSIDERAĢÕES FINAIS}

Este artigo analisou o processo de adoção da certificação verde $L E E D$ com base nos estabelecimentos do setor hoteleiro que já a adotaram. Ofereceu, primeiramente, uma visão geral quanto ao desenvolvimen- 
to para, a seguir, apontar as discussões da literatura quanto ao uso de construções verdes e sua certificação em projetos de empreendimentos hoteleiros. Por fim, a análise dos dados apontou pontos positivos e negativos percebidos pelos meios de hospedagem que a adotam, bem como uma tendência ao crescimento da adoção desse tipo de certificação por meios de hospedagem dos mais diversos portes e categorias.

Algumas dificuldades de implantação foram reportadas, o que demonstra que não é fácil conseguir a certificação, e os estabelecimentos hoteleiros têm realmente que se atentar aos padrões estabelecidos, o que se, por um lado, exige trabalho, por outro, dá maior valor ao selo, quando conseguido. Alguns autores, como Hernandes (2006), colocam algumas ressalvas quanto ao uso do $L E E D$ no Brasil, principalmente em relação às características do País e suas particularidades. Ainda assim, esse mesmo autor salienta que "qualquer que seja a conclusão de um juízo de valores sobre o sistema, ele ainda se mantém como uma das referências mais influentes ao nosso alcance" (HERNANDES, 2006, p. 124).

Até que ponto os processos contribuem, de fato, para um desenvolvimento sustentável ou em que medida as organizações certificadoras abordam as questões paradigmáticas de um desenvolvimento sustentável não foi verificado no presente estudo, devido ao seu objetivo exploratório inicial, mas fica como interessante possibilidade para novos estudos. Verificou-se, porém, que, ao menos aparentemente, há uma consciência crescente de que os padrões da sociedade industrial de consumo e produção balizados pelo esbanjamento dos recursos não podem manter-se em longo prazo. $\mathrm{O}$ setor hoteleiro não é alheio aos potenciais benefícios financeiros, de vantagem competitiva e de reputação dessa conscientização, mas não reportam a questão da manutenção de suas operações em longo prazo.

O fato de haver esforços para adaptação da $L E E D$ às realidades locais parece interessante na medida em que os indicadores de mensuração das práticas dos estabelecimentos se atrelariam mais aos modos históricos, socioculturais, econômicos e naturais locais, mas qual a flexibilidade máxima do sistema e como as grandes cadeias hoteleiras que atuam em diversos países lidariam com essas diferenças são pontos de indagação interessantes para quando houver mais versões locais da certificação e mais estabelecimentos certificados fora do país de origem da certificação.

A pesquisa apresenta implicações práticas tanto para a gestão socioambiental de meios de hospe- dagens quanto para outros estabelecimentos e para a certificadora, apontando que há múltiplas razões para a adoção da certificação, mas que os benefícios percebidos se concentram principalmente na área financeira e que há ainda outras dimensões a serem mais bem exploradas. Além disso, contribui para o debate acadêmico da gestão e certificação ambiental no setor de turismo e aponta diversas lacunas que podem ser aprofundadas, como: se essa certificação está se institucionalizando em algumas cadeias hoteleiras internacionais; a relação entre a categoria ou segmento hoteleiro com o interesse em se certificar e importância dada a essa ação por parte dos hóspedes de cada nicho; a viabilidade da certificação para estabelecimentos econômicos, entre outras. Possui limitações, como a inexatidão dos projetos de meios de hospedagem em certificação, devido à confidencialidade de processos. Além disso, um retorno mais próximo do universo da pesquisa poderia enriquecer ainda mais o trabalho.

\section{REFERÊNCIAS}

ASSOCIAÇÃO BRASILEIRA DA INDÚSTRIA DE HOTÉIS. Perfil da ABIH e projeções. Disponível em: http://www. abih.com.br/Inst_ABIH.php. Acesso em 02.02.2009.

BARDIN, L. Análise de conteúdo. Lisboa: Edições 70, 1977.

BECKER, E. J. The proximity hotel: a case study on guest satisfaction of sustainable luxury environments. Greensboro: University of North Carolina (Master of Science), 2009.

BUTLER, J. The compelling "hard case" for "green" hotel development. Cornell Hospitality Quarterly, v. 49, n. 3, p. 234-244, 2008.

COMISSÃO MUNDIAL SOBRE MEIO AMBIENTE E DESENVOLVIMENTO. Nosso futuro comum. 2. ed. Rio de Janeiro: Fundação Getúlio Vargas, 1991.

CROUS, Y. e outros. 2008 Global Vision Awards. Travel + Leisure. Disponível em: http://www.travelandleisure.com/ articles/2008-global-vision-awards. Acesso em 12.12.2009.

D'SOUZA, C. Ecolabels programmes: a stakeholder (consumer) perspective. An International Journal, v. 9, n. 3, p. $179-188,2004$. 
ENVIRONMENTAL PROTECTION AGENCY (EPA). Environmental labelling: issues, policies and practices worldwide. Washington, DC: EPA, 1998.

FONT, X. Environmental certification in tourism and hospitality: progress, process and prospects. Tourism Management, v. 23, n.3, p. 197-205, 2002.

FONT, X. Sostenibilidad y alivio de la pobreza en países en vías de desarrollo: el papel del hotelero y del investigador. Estudios y Perspectivas en Turismo, v. 17, p. 7-28, 2008.

FOSTER, S. T; SAMPSON, S. E; DUNN, S. C. The impact of customer contact on environmental initiatives for service firms. International Journal of Operations \& Production Management, v. 20, n. 2, p. 187-203, 2000.

FRANCH, M. R. B; IZQUIERDO, M. A. F; TORRES, M. J. M. La responsabilidad social de la empresa. València: Generalitat, 2007.

FREITAS, A. L. P; ALMEIDA, G. M. M. Avaliação do nível de consciência ambiental em meios de hospedagem. Sociedade E Natureza, v. 22, n. 2, p. 405-417, 2010.

GREEN BUILDING COUNCIL BRASIL (GBC). Disponível em: http://www.gbcbrasil.org.br. Acesso em 05.05.2008.

GREEN BUILDING COUNCIL BRASIL (GBC). Guia para sua obra mais verde. São Paulo: Green Building Council Brasil, 2009.

GUERRA, A; PÁJARO, E. Empresas turísticas en España: ¿̨ocialmente Responsables? CULTUR, v. 5, n. 2, p.43-60, 2011.

HERNANDES, T. Z. LEED-NC como sistema de avaliação da sustentabilidade: uma perspectiva nacional? 2006. 134 f. Dissertação de Mestrado em Arquitetura, FAUSP, São Paulo, 2006.

HILL, R. C; BOWEN, P. A. Sustainable construction: principles and a framework for attainment. Constrution Management and Economics, v.15, n.3, p. 223-239, 1997.

HUSTED, B. W; DE JESÚS, J. Taking friedman seriously: maximizing profits and social performance. Journal of $\mathrm{Ma}$ nagement Studies, v. 43, n. 1, p. 75-92, 2006.

INSTITUTO DE HOSPITALIDADE. Guia de interpretação da norma: "meios de hospedagem - requisitos para a sustentabilidade". Sem data. Disponível em: http:// www.biblioteca.sebrae.com.br/bds/BDS.nsf/. Acesso em 04.04.2010.

JANÉR, A. Programa de Certificação em Turismo Sustentável. São Paulo: Instituto de Hospitalidade, 2010.

JOHN, G; CLEMENTS-CROOME, D; JERONIMIDIS, G. Sustainable buildings solutions. Building and Enviroment, v. 40, n. 3, p. 319-328, 2005.

KASIM, A. Socio-environmentally responsible hotel business: do tourists to Penang Island, Malaysia care? Journal of Hospitality \& Leisure Marketing, v. 11, n. 4, p. 5-28, 2004.

KATZ, G. H. Green building costs and financial benefits. Westborough: Massachusetts Technology Collaborative, Renewable Energy Trust, 2003.

KOHLER, N. The relevance of green building challenge: an observer's perspective. Building Research \& Information, v. 27, n. $4 / 5$, p. 309-320, 1999.

LUBBERT, C. Tourism ecolabels market research in Germany. In: FONT, X; BUCKLEY, R. (Eds). Tourism ecolabelling: certification and promotion of sustainable management. Wallingford: CAB International, 2001.

MANAKTOLA, K; JAUHARI, V. Exploring consumer attitude and behavior towards green practices in the lodging industry in India. International Journal of Contemporary Hospitality Management, v. 19, n. 5, p. 364-377, 2007.

MARGOLIS, J. D; WALSH, J. P. Misery loves companies: rethinking social iniciatives by business. Administrative Science Quarterly, v. 48, n. 2, p. 268-305, 2003.

MUSKA, A. The challenge of independent corporate environmental performance evaluation. In: PIASECKI, B; FLETCHER, K; MENDELSON, F. (Eds). Environmental Management and Business Strategy. Chichester: John Wiley \& Sons, 1998. p. 323-325.

ORELLANO, V. I. F; QUIOTA, S. Análise do retorno dos investimentos socioambientais das empresas brasileiras. $R A E$, v. 51, n. 5, p. 471-484, 2011.

ORLITZKY, M; SCHMIDT, F. L; RYNES, S. L. Corporate social and financial performance: a meta-analysis. Organization Studies, v. 24, n. 3, p. 403-441, 2003. 
KUHRE, W.L. ISO 14020s: Environmental Labelling-marketing. Upper Saddle River, NJ: Prentice-Hall, 1997.

RETTAB, B; BRIK, A. B; MELLAHI, K. A study of management perceptions of the impact of corporate social responsibility on organizational performance in emerging economies. Journal of Business Ethics, v. 89, n. 3, p. 371390, 2009.

SACHS, I. Desenvolvimento: includente, sustentável, sustentado. Rio de Janeiro: Garamond, 2004.

SASIDHARAN, V; SIRAKAYA, E; KERSTETTER, D. Developing countries and tourism ecolabels. Tourism Management, v. 23, n. 2, p. 161-174, 2002.

SCOTTO, G; CARVAlHO, I. C. de M; GuimarÃES, L. B. Desenvolvimento sustentável. Petrópolis: Vozes, 2007.

TZSCHENTKR, N; KIRK, D; LYNCH, P. A. Reasons for going green in serviced accommodation establishments. International Journal of Contemporary Hospitality Management, v. 16, n. 2, p. 116-124, 2004.

USGBC. LEED rating system. Disponível em: http://www. usgbc.org. Acesso em 06.06.2009.

VEIGA, J. E. Desenvolvimento sustentável: o desafio do século XXI. Rio de Janeiro: Garamond, 2005.

WAGNER, M; SCHALTEGGER, S. How does sustainability performance relate to business competitiveness? GMI, v. 44, n. 44, p. 5-16, 2003.

WASIK, J. Green marketing and management: a global perspective. Oxford: Blackwell, 1996.

ZAMBONIM, F. M. Gestão e certificação ambiental para hotéis. 2002. 126 f. Dissertação de Mestrado em Engenharia Ambiental, UFSC, Florianópolis, 2002. 